\title{
On the System Construction of Citizen Moral Construction
}

\author{
Zhongyan Yang \\ Feixian Campus, Linyi University, Linyi, Shandong, China \\ fxsfyzy@126.com
}

Keywords: Citizen; Morality; Moral construction; System's construction

\begin{abstract}
Moral construction is an important part in the construction of socialist spiritual civilization. Since the reform and opening up to the outside world, the moral construction of our country has made great progress, but at the same time, moral field also appeared some bad phenomena. The reason, to a large extent, is due to the lack of system's support in the moral construction. Therefore strengthening the system's construction in the moral construction has a far-reaching significance to improve the current moral situation of our country and to promote the construction of spiritual civilization of our country.
\end{abstract}

\section{Introduction}

The "citizen morality construction implementation outline" issued by the Central Committee of the Communist Party of China in August, 2001, pointed out: "moral construction is a complex social system project, and it relies on education, and depends on the law, policies and regulations system."That's to say, the outline clears that the system's construction is the indispensable content for strengthening the citizen moral construction at the present stage of our country. Comrade Deng Xiaoping once pointed out: "if the problem of the system does not solve, the problem in thought style will not be solved." Therefore, strengthening the system's construction is of great significance in the process of strengthening the ideological and moral construction of citizens.

System generally refers to the requirements which we should abide by the rules or guidelines for action, or the certain rules, laws, customs and so on under the certain historical conditions. The system can be divided into formal institutions (such as the rules or the law) and informal institutions (such as the behavioral norms, customs, or behavior criterion). Institutional support in moral construction refers to the improvement of the moral theory through this external forces of system's heteronomy, and through system's clear, authoritative, mandatory unique advantages to promote the steady improvement of the moral quality and social moral environment, moral mood and the optimization of the moral relationship.

\section{The Importance of Strengthening the Construction of the System in the Citizens' Moral Construction}

First, to Strengthen the System Construction in the Civil Moral Construction, Will Be Beneficial to Make Up the Moral Defects and Improve the Moral Authority. Morality is used to adjust and regulate people's behavior through the inner belief, public opinion and traditional habits, but it is binding only by accepting it wholeheartedly, and changing into their own feelings, the conviction and the will. This determines that its punishment to the unethical behavior is a kind of concept, public opinion and non-mandatory, which is a kind of soft binding. And this kind of soft constraints is often incapable of action facing those people without moral consciousness and conscience of bankrupt. And institutional constraints on people's behavior is mandatory, that is, no matter what the system is, people must comply with the system. It can be said that the moral defects of the system is the moral advantage, which laid the social psychological foundation for the system of rules and regulations, which pointed out the direction for the establishment of civil moral basic values and moral practice. Both of them have the relationship between the intrinsic unities. In the moral 
Construction, Using system can make up moral defects to promote moral norm transformation into people's beliefs and the ability to self -restraint, and raise moral authority in order to better enhance people's moral consciousness, in order to strengthen people's understanding to assume their responsibilities and obligations, which encourages people to choose moral behavior and maintain the good social morals.

Second, to Strengthen the System Construction in the Civil Moral Construction Is Conducive to Better Solve the Problem of Civic Morality, Which Ensures the Healthy and Orderly Development of the Socialist Market Economy. The establishment and development of socialist market economy enhances people's autonomy, self consciousness. The pursuit of scientific, civilized, healthy lifestyle has become the conscious action of the people, which is the mainstream of citizen moral construction. However, this process also leads to some moral anomie phenomenon. Some people ignore the law, ignore the moral, betray the personality, make and sell fake money. Some people almost commit all sorts; egoistic, mercenary, money worship and pursuit of pleasure. Some Party members have cadres of corruption, and corruption, and taking bribes. If this doesn't effectively curb the phenomenon, it not only will corrupt social values, but also damage the normal order of the market economy and social atmosphere. To change this phenomenon, it has been far from enough only by relying on the moral education and moral propaganda typical tree and do the deeds of the report. To make the moral construction in the system fruitful, we must make a difference in arrangements, try to seek institutional support in moral construction, and use the civil moral norms of the system to solve these problems. Therefore, to strengthen the system construction of citizen morality is the main way to solve the problem of citizen moral anomie to ensure the development of the socialist market economy.

Third, Strengthening the System Construction in the Civil Moral Construction Is Conducive to Ensure the Effectiveness of Citizens' Moral Norms, Which Forms a Good Social Environment for Moral Construction. The effectiveness of citizen ethics refers to the situation which is actually complied with moral norms itself, which is the key point of moral construction. A society often is not the lack of moral norms, but the lack of citizen moral norm compliance. Our current situation for moral norms' abidance by, although people consciously abide by the A growing awareness, the effect is not very ideal. Generally there is a "none of my business, an armchair mentality of immoral behavior, and people are often indifferent. Besides, there is still a condemned " phenomenon:" good behavior is not his evil behavior. Therefore, in modern society, it is not enough to use self-discipline the supervision of public opinion on spontaneous citizens to achieve the effectiveness of moral norms, which must also, has their outside authority support. This requires that we must strengthen the construction of citizen moral system Construction. Only with the constraints of the moral system, the formation of a general binding system environment, people will be generally consciously abided by the ethical norms. The effectiveness of the moral norms of citizens will be reflected.

Fourth, Strengthening the System Construction in the Civil Moral Construction Is Conducive to Ensure the Smooth Progress of Moral Construction. Moral construction involves many important theoretical issues on the grasp at all times and in all countries. At the same time, it's also a practical operation and the actual practice of the problem. The characteristics of moral construction is a long-term and recurrent macroscopic sociality. So the moral construction is a complicated system engineering and the difficulty of moral construction practice. First, the moral construction requires a complete set of functions and leading organizations to determine the overall planning of the moral construction of the whole society and specific process. Secondly, moral construction also needs professional researchers and institutions to provide scientific theoretical guide and the analysis of the present situation for the decision. Again, moral construction related to people's living environment and has far-reaching influence. If moral construction once the decision-making mistakes will not only cause harm to the social atmosphere and the living environment of the whole society, but also affect several generation of people's moral quality and social stability. Therefore, moral construction with the construction of legal system, political and 
economic construction must be scientific, careful and prudent, can not act blindly, which requires a good professional research team to give advice to the practice of moral construction. In addition, moral construction must also have a set of perfect evaluation and assessment mechanisms. Scientific and perfect evaluation and examination mechanism will be able to continue to moral construction of feedback information effectively. Evaluation and assessment mechanism for the overall process of moral construction, modification and perfection of decision making of moral construction, and innovation of moral construction method will play an important supporting role.

Anyway, these specific tasks of moral construction can not be completed at one's will, must be carefully designed and institutional arrangements, and make a scientific arrangement for the guiding ideology of moral construction, the leadership mechanism, mode, participation main body and target tasks.

To sum up, in a system which is not perfect or imperfect of social environment for moral construction, its difficulty is imagined. To improve the moral quality of members of society, enhance the effectiveness in the moral construction, we must take measures from the research on the system of moral construction of the safeguard and the promoter action to proceed, strengthen and improve the institutional arrangements. Conversely, moral construction without system support is far from the reality of social existence and become empty preaching. The goal of moral construction will become a castle in the air.

\section{The Recommendations of Strengthening the Construction of the System of Civil Moral}

First, to Establish and Perfect the System of Civil Moral Norms of the Protection Mechanism. To improve the protection mechanism of system of citizen morality will regulate the behavior and process system of static norms of citizen morality into citizen moral system dynamics, which is the requirement for the implement of system of citizen moral. Firstly, to establish and improve the leadership mechanism are the key to ensure the smooth construction of citizen moral norms start system and the operation's start. Secondly, to establish and perfect the mechanism of public opinion is essential to safeguard mechanism system of citizen morality. It can make the citizen moral by a rational design into a moral expression from forced into internal constraint outward, and achieve moral self-discipline, change passive to active moral ethics, which makes moral behavior become conscious requirement. Thirdly, to establish a sound education mechanism. The citizen's moral education mechanism is the basic means of citizen moral construction for the implementation of citizen moral system. Fourthly, it is necessary to establish and improve the system structure of mutual checks and balances, which is an important stabilizing factor to ensure the implementation of the norms of citizen moral system. Specifically, it is to ensure that the citizen moral system specification and implementation of the political system, economic system, cultural system, the system of science and technology, system environment, so as to promote coordinated development with each other.

Second, to the Construction of the Specific System of Civil Ethics Norms. The Construction of specific civil moral behavior norms of the system is the core content of the system construction of citizen moral construction. According to the main content of citizen moral norms of the system, it can use roughly three aspects from the social morality, professional ethics, and family virtues to construct the specific moral norms of the system. To build social morality will be in accordance with the general requirements such as civility, politeness, helpfulness, take good care of public property, environmental protection, law-abiding. To build professional ethics will be in accordance with the general requirements such as dedication, honesty, impartiality, serve the people, contributing to society. To building family virtues will be in accordance with the general requirements such as respecting to old and young, gender equality, and harmony of couples, thrifty, neighborhood unity.

Third, to Promote the Institutionalization of Moral Principles and Norms. Norms and moral principles of the system is a part of the basic moral norms and moral requirements through legal procedure conversion system, laws and regulations, public policy, authority, relying on the system, mandatory to be promoted. The moral principle and norm system will enhance the moral authority and 
operability, thereby it will strengthen the force of moral norms and promote members of the community to accept social moral values and norms.

The institutionalization of moral principles mainly has the following three ways:

(1) The moral legalization. Transforming moral principles into law and legislation by virtue of the principle of morality to give full play to the legal force of the law. In the actual social life, there are all kinds of moral, but not all moral should be carried out through legal means or with the support of the law. Only those with historical rationality and reflecting the wishes and interests of the general public and necessary for society, should be legalized by the force of the country to ensure the implementation of the moral. To make it universally blinding on the members of society.

(2) Moral policy. Based on the government or authority advocated some moral principles to arrange a behavior oriented mechanism to social rewards and punishment as the core, to make these norms become general behavior of the public. When the government and its departments are making various policies, they should incorporate moral principles and requirements to regulate and guide the interests of moral subject. This will have a strong guiding role in people's moral life.

(3) Moral rules and regulations. When the basic units of various sectors and industries by Region are establishing and perfecting all kinds of administrative rules and regulations, according to the different customs and habits, requirements of the industry, they should integrate moral principles into them to strengthen supervision and inspection and carry out the implementation.. Such as some local labor regulations for place "no smoking", which is code of ethics. At the same time, they have the provisions will be fined. This has become the following moral system to protect it.

Fourth, the Construction of Moral Security System. Good and reasonable moral security system can make people realize that virtue is not only beautiful, but also useful to guide people to perform good deeds. The moral guarantee system construction will create a moral mechanism. Making the social members aware of virtue is the pass of society, and it is the basic way to get their legitimate interests, but also an indispensable person to settle down. It may bring their own conscience, personality, self-esteem, social recognition. Secondly, to establish strict moral supervision system is to make full use of radio, television, newspapers and other mass media, through the ethical evaluation of moral behavior and make value judgment, and the value judgment feedback to the person himself, mobilize the actors a sense of honor and conscience, which is their moral behavior and their pride Flourish, to their own immoral behavior shame, and corrected in a timely manner, so as to enhance the behavior main body knows good knowledge capacity of evil and establish from good to bad attitude. Thirdly, we must establish moral reward and punishment system. That is, to entities and individuals that make outstanding contributions in moral practice, and to give a certain material and spiritual rewards, in flagrant violation of moral individuals or organizations of the material and spiritual double punishment. Through reward and punishment, it will promote people to consciously choose moral behavior by weighing the pros and cons, so as to promote the internalization of social ethics, prompting people to perform good deeds.

A society of moral status, to a large extent, it is up to the institutional arrangements that society has made. If the social system is reasonable, fair, sound and displays specific, clear, system of moral, moral construction will have the barrier and relying on. In the process of moral construction, we should not only advocate individual initiative and self-consciousness, but also actively seek the guidance of the system to support and protect. To realize the positive interaction between moral construction and institutional arrangement. To reasonably grasp the limits of the moral construction of the system. Promote the healthy development of moral construction in our country.

In a word, to strengthen the system construction of citizen moral construction still has certain difficulties in the practice, but in theory it is feasible. As long as we base on the reality and insist in the principle to establish specific moral system around the operation of the market economy, we can promote people's all-round development, cultivate a generation after generation of "Four Haves" citizens through moral construction. 


\section{References}

[1] Qian Guangrong. Ethical system: social security mechanism of moral construction, Journal of Changchun municipal Party school, 2002 (9).

[2] Fu Shifang. Community moral construction [M]. Southwestern Normal University press, 2003, 241st pages.

[3] Wu Junyue. [M]. thinking about strengthening the moral construction of citizens of Ningbo journal, 2002 (3).

[4] MAO yushi. the Chinese moral outlook [M], guangzhou jinan university press, 2003.

[5] Wu Aiying. The theory of socialist spiritual civilization construction [M], jinan, shandong people's publishing house, 2003 edition.

[6] Chen Wei. The role of the system of moral construction in the first 2006 (4) in the moral construction.

[7] Tan Chuanjie. [J], the mechanism of interaction between morality and system arrangement of the south of the Five Ridges journal, 2004 (1).

[8] Zhao Ganfu. The possibility of legal support for the construction of socialist morality [J], Journal of Henan Vocational College of Judicial Police Officers, 2006

[9] Yang Ruhua, on the social transition period of moral disorder and moral reconstruction [J], Journal of Kunming University, 2004 (1).

[10] Xiong Jiansheng, on the moral construction of citizens of the legal support [J], moral education research. 2004 (1). 